\title{
The GC-box is critical for high level expression of the testis-specific Hsp70.2/Hst70 gene
}

\author{
Wiesława Widłak ${ }^{\bowtie}$, Natalia Vydra, Volha Dudaladava, Dorota Ścieglińska, \\ Bolesław Winiarski and Zdzisław Krawczyk \\ Department of Tumor Biology, Maria Skłodowska-Curie Memorial Cancer Center and Institute of Oncology, \\ Gliwice Branch, Gliwice, Poland
}

Received: 29 August, 2006; revised: 18 December, 2006; accepted: 12 January, 2007

available on-line: 20 February, 2007

\begin{abstract}
The Hsp70.2/Hst70 gene, which belongs to the $70 \mathrm{kDa}$ heat-shock protein (HSP) family, is expressed specifically in primary spermatocytes and spermatids. The regulatory elements required for a high level of testis-specific expression of the gene are placed between the two major transcription start sites T1 and T2 (approximately 350 and $115 \mathrm{bp}$ upstream of the starting ATG codon). Here we have shown that sequences proximal to the exon1/intron splicing site in the $5^{\prime}$ untranslated region of the $H s p 70.2 / H s t 70$ gene, which include a highly conserved element called box $B$, are required for efficient expression of the chloramphenicol acetyltransferase reporter gene in testes of transgenic mice. However, in spite of the drastically reduced overall activity, the stagespecific expression pattern of the transgene was preserved after removal of these sequences. We have also shown that GC-box located downstream of the box B (approximately 210 bp upstream of the starting ATG codon) is indispensable for efficient expression of the Hsp70.2/Hst70 gene promoter in spermatogenic cells. The GC-box specifically binds proteins present in nuclear extracts from testes (putatively Sp1-like factors). A change in the pattern of such GC-box-interacting factors corresponds to activation of the Hsp70.2/Hst70 gene, confirming the importance of this regulatory element.
\end{abstract}

Keywords: regulation of gene expression, heat shock protein, spermatogenesis, GC-box, Sp1

\section{INTRODUCTION}

Spermatozoa develop in testes from spermatogonial stem cells in a process involving a series of mitotic/meiotic divisions and differentiation events. Male germ-cell differentiation requires stage- and cell-specific regulation of gene expression that is achieved by unique chromatin remodeling, transcriptional control and expression of testis-specific genes or isoforms. One of the testis-specific genes is a $70 \mathrm{kDa}$ heat shock protein gene, named Hsp70.2 in mouse, Hst70 in rat and HSPA2 in human (Zakeri et al., 1988; Krawczyk et al., 1988a; Bonnycastle et al., 1994). The rodent Hsp70.2/Hst70 gene is expressed almost exclusively in spermatocytes and spermatids (Krawczyk et al., 1988b; Allen et al., 1988). The gene codes for a molecular chaperone protein necessary for completion of meiotic division. In Hsp70.2(-/-) male mice synaptonemal complexes fail to disassemble and primary spermatocytes arrest in meiosis I and undergo apoptosis, which leads to infertility (Dix et al., 1996).

The Hsp70.2 and Hst70 genes have an identical organization in their promoter regions. Transcription of both genes is initiated at two major start sites, T1 and T2, localized approx. 350 and 115 bp upstream of the starting ATG codon, respectively. Transcripts generated at the $\mathrm{T} 1$ site contain a

Corresponding author: Wiesława Widłak, Department of Tumor Biology, Maria Skłodowska-Curie Memorial Cancer Center and Institute of Oncology, Gliwice Branch, 44-101 Gliwice, Poland; tel: (48 32) 278 9669; fax: (48 32) 231 3512; e-mail: wwidlak@io.gliwice.pl

Abbreviations: CAT, chloramphenicol acetyltransferase; DTT, dithiothreitol; FBS, fetal bovine serumł HSP, heat shock protein; Hsp70, 70 kDa multigene family of heat-shock or 'stress' genes; mut, mutated; Oct, octamer; PMSF, phenylmethylsulfonyl fluoride; Sp1, transcription factor named according to the original purification scheme that included Sephacryl and phosphocellulose columns; TBE buffer, Tris/borate/EDTA buffer; T1 and T2, transcription start site 1 and 2; tk, thymidine kinase. 
$239 \mathrm{bp}$-long intronic sequence that is subsequently spliced out (Ścieglińska et al., 2001). The T2 site located in the intron is preceded by a canonical TATA box (diagram in Fig. 1). However, only the T1 site is functionally important in cells that actually produce the HSP70.2/HST70 protein. Activation of the T1 site is associated with the release of a putative repressor from the Oct sequence, localized directly downstream of the T1 site (Ścieglińska et al., 2004).

Functional analysis of the Hsp70.2/Hst70 gene promoter revealed that all regulatory elements required for a high level of testis-specific expression are located between the T1 and T2 transcription start sites (Widłak et al., 1994; 1995; Ścieglińska et al., 2001). Two regions of high homology between the Hsp70.2 counterparts from different species, boxes A and $\mathrm{B}$, are of particular interest. We showed previously that removal of the T1 site and proximal box A totally abolishes the activity of the Hsp70.2/Hst70 promoter (Ścieglińska et al., 2001). In this work we aimed to assess the role of sequences located in box $\mathrm{B}$, placed around the exon1/intron splicing site, in the regulation of the $H s p 70.2 / H s t 70$ gene expression.

\section{MATERIALS AND METHODS}

Recombinant plasmids. The pHST(368/62)CAT6 plasmid was constructed by inserting the BstXI(-368)-DraII(-62) fragment of the rat Hst70 gene (GenBank accession no. $\underline{\mathrm{X} 15705}$ ) in front of the pro-

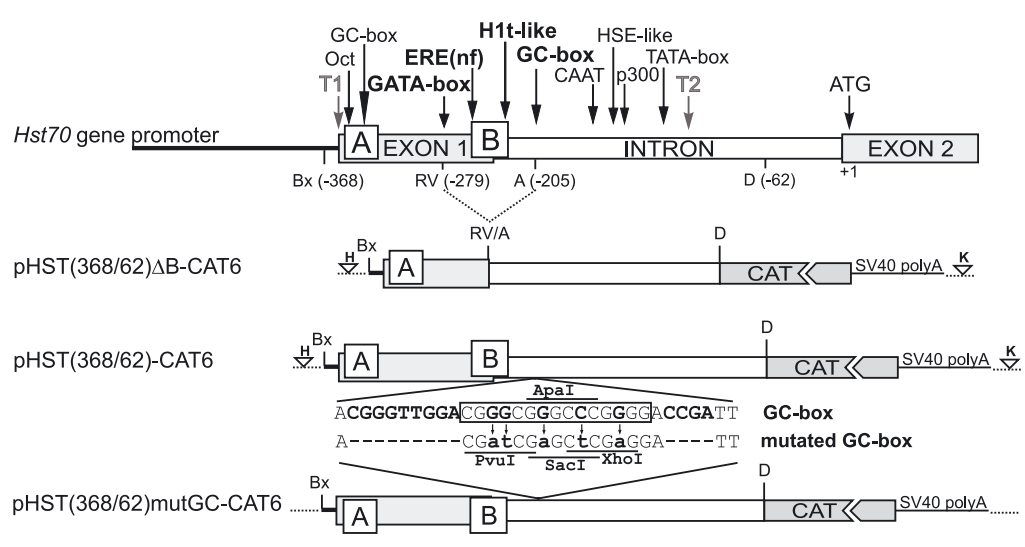

Figure 1. Structure of the Hst70 gene promoter and transgenes used in analyses.

Vertical arrows denote positions of the two main transcription start sites (T1 and T2) and putative cis-regulatory elements. Exons and regions of perfect homology between rat, mouse and human counterparts (boxes A and B) are shown as rectangles. BstXI, EcoRV, ApaI, DraII, HindIII and $\mathrm{K} p n \mathrm{I}$ restriction sites are abbreviated as $\mathrm{Bx}, \mathrm{RV}, \mathrm{A}, \mathrm{D}, \mathrm{H}, \mathrm{K}$, respectively, and their coordinates are related to $\mathrm{A}(+1)$ in the starting ATG codon. The ligation between EcoRV and ApaI restriction sites (blunted with T4 DNA polymerase) is marked as RV/A. Open triangles indicate the polylinker restriction sites used to cut out the hybrid gene for microinjection. A boxed sequence represents the most likely location of the functional GC-box. The bolded bases in the GC-box were changed as indicated to obtain the mutated GC-box. moterless CAT gene cloned in the pBLCAT6 plasmid (GenBank accession no. M80484), as described earlier (Widłak et al., 1995). To obtain pHST(368/62) $\Delta \mathrm{B}$ CAT6 plasmid the EcoRV(-279)-ApaI(-205) fragment of the rat $H s t 70$ gene promoter was removed from the pHST(368/62)-CAT6 plasmid. The pHST(368/ mutGC-CAT6 plasmid was obtained from pHST(368/62)-CAT6 plasmid by PCR-mediated sitethe ATG codon of the $H s t 70$ coding sequence.

Generation of transgenic mice. Transgenic mice were engineered as described in details elsewhere (Widłak et al., 1995). Plasmids used for microinjection were digested with HindIII and KpnI in order to remove vector sequences, and then appropriate restriction fragments were microinjected nto the pronuclei of zygotes from $\mathrm{FVB} / \mathrm{N}$ females yy standard procedures. Transgenic founders were seened by PCR using genomic DNA isolated from mal Experimentation.

Analysis of CAT activity. Analysis of the chloramphenicol acetyltransferase (CAT) activity was performed as described previously (Ścieglińska et al., 2001). CAT assay mixtures contained $10-150$ $\mu \mathrm{g}$ of protein and samples were incubated for $15 \mathrm{~min}$ to $5 \mathrm{~h}$ at $37^{\circ} \mathrm{C}$. CAT activities were expressed in arbitrary units defined as the percentage of chloramphenicol converted into acetylated products during one hour in a reaction involving one milligram of protein extract (Pothier et al., 1992). Total protein content was determined using a Protein Assay Kit (BioRad).

Transfection of somatic cells. Plasmid DNA was transiently transfected into human HCT116 cells with Dharmafect reagent (Dharmacon) according to the manufacturer's protocol. Briefly, cells were seeded at $2 \times 10^{4}$ cells per $35 \mathrm{~mm}$ culture dish $24 \mathrm{~h}$ before transfection. Two micrograms of pHST-CAT plasmids and $4 \mu \mathrm{l}$ of Dharmafect in appropriate volume of medium were used for single transfection. Cells were incubated with trans- 
fection mixture for $4 \mathrm{~h}$, then it was removed and replaced by medium McCoy containing 10\% FBS. Cells were harvested $48 \mathrm{~h}$ after transfection for analyses of CAT activity.

Electroporation of testis. Electroporation was performed as described in details elsewhere (Widłak et al., 2003). Fifty microliters of a solution containing $80 \mu \mathrm{g}$ of the pHST-CAT plasmid and $10 \mu \mathrm{g}$ of the control pEGFP-GL3 plasmid (the enhanced green fluorescent protein gene under control of the SV40 promoter used to monitor the electroporation efficiency) was injected directly into seminiferous tubules of each testis. Electric pulses were applied to each testis 8 times at $40 \mathrm{~V}$ for $50 \mathrm{~ms}$. Testes were dissected and processed for the CAT activity assay $24 \mathrm{~h}$ after electroporation.

Preparation of nuclear extracts. Freshly dissected tissues were homogenized in ice-cold low salt buffer consisting of $10 \mathrm{mM} \mathrm{KCl}, 0.25 \mathrm{M}$ saccharose, $1.5 \mathrm{mM} \mathrm{MgCl}_{2}, 0.5 \mathrm{mM}$ EGTA, $1 \mathrm{mM}$ DTT, 0.5 $\mathrm{mM}$ PMSF, $10 \mathrm{mM}$ Tris/HCl, $\mathrm{pH}$ 7.4, and a protease inhibitor mixture (Complete ${ }^{\mathrm{TM}}$, Roche), supplemented with $0.5 \%$ Nonidet P- 40 . Homogenates were filtered using gauze and nuclei were sedimented by centrifugation $\left(5 \mathrm{~min}, 900 \times \mathrm{g}\right.$ at $4^{\circ} \mathrm{C}$ ), washed in the low salt buffer then in the same buffer containing $100 \mathrm{mM} \mathrm{KCl}$. Nuclear proteins were extracted by incubation for $30 \mathrm{~min}$ at $4^{\circ} \mathrm{C}$ in a high salt buffer consisting of $0.4 \mathrm{M} \mathrm{NaCl}, 10 \mathrm{mM}$ Hepes/NaOH ( $\mathrm{pH} 7.9), 1.5 \mathrm{mM} \mathrm{MgCl}{ }_{2}, 0.1 \mathrm{mM}$ EGTA, $0.5 \mathrm{mM}$ DTT, 5\% glycerol and a protease inhibitor mixture (Complete $^{\mathrm{TM}}$, Roche). Insoluble remnants of the nuclei were pelleted by centrifugation for $30 \mathrm{~min}$ at $16000 \times g$ at $4^{\circ} \mathrm{C}$. The resulting supernatants were referred to as nuclear extracts. The protein concentration was assayed using the Protein Assay Kit (BioRad).

Electrophoretic mobility-shift assay. Complementary single stranded oligonucleotides were annealed in aqueous solutions to obtain doublestranded DNA probes. The sequences of the probes were as follows: Sp1-cons - 5'-GGT GCT CGC CCC GCC CCG ATC GAA TGA TTG; GC-box - 5'-GGT TGG ACG GGC GGG CCC GGG GAC CGA TTG; mutGC - 5'-CGC TGG ACG ATC GAG CTC GAG GAT TGG CTC. The DNA probes were labeled with $\left[\gamma^{32} \mathrm{P}\right] \mathrm{dATP}$ using T4 polynucleotide kinase and purified from nondenaturating polyacrylamide gels. The probes $(20 \mathrm{ng})$ were incubated with nuclear extracts $\left(5 \mu \mathrm{g}\right.$ of protein) for $30 \mathrm{~min}$ at $4^{\circ} \mathrm{C}$ in a binding buffer consisting of $20 \mathrm{mM}$ Tris/ $\mathrm{HCl}(\mathrm{pH}$ 7.6), 5 $\mathrm{mM} \mathrm{MgCl}{ }_{2}, 1 \mathrm{mM}$ EDTA, $1 \mathrm{mM}$ DTT, 5\% glycerol and $200 \mathrm{mM} \mathrm{NaCl}$, in the presence of a ten-fold excess of non-radioactive poly (dI-dC) double-stranded alternating copolymer used as a non-homologous competitor, in a final volume of $20 \mu \mathrm{l}$. Nucleoprotein complexes were resolved by electrophoresis on
$6 \%$ nondenaturing polyacrylamide gels in a $0.5 \times \mathrm{TBE}$ running buffer. Gels were dried and autoradiographed.

\section{RESULTS AND DISCUSSION}

We have aimed to establish the role of the highly conserved DNA sequences localized around the exon1/intron splicing site (box B) in the regulation of the Hsp70.2/Hst70 gene expression. The $75 \mathrm{bp}-$ long EcoRV(-279)-ApaI(-205) restriction fragment of the rat $H s t 70$ gene promoter was removed from the pHST(368/62)-CAT6 reporter transgene, which was previously shown to have the highest specific activity in testes of transgenic mice (Widłak et al., 1995). The resulting pHST(368/62) $\triangle \mathrm{B}-\mathrm{CAT} 6$ construct (Fig. 1) was used to generate new lines of transgenic mice. The average CAT activity was calculated from four such transgenic lines (the transgene expression was completely absent in two other lines). The activity of CAT was assayed in testes of mature mice, carrying either the pHST(368/62) $\triangle \mathrm{B}-\mathrm{CAT} 6$ or the pHST(368/62)-CAT6 transgene. A comparison of the expression of the two transgenes revealed that removal of the EcoRV-ApaI fragment resulted in an about 50-fold reduction of CAT expression (Fig. 2A), proving the importance of the analyzed sequences for the activity of the Hsp70.2/Hst70 gene promoter.

The expression of both pHST(368/62) $\triangle \mathrm{B}-\mathrm{CAT} 6$ and pHST(368/62)-CAT6 transgenes was analyzed also in the course of the postnatal development of mice. In spite of the drastically reduced overall activity, the stage-specific expression pattern of the transgene in pHST(368/62) $\triangle \mathrm{B}$-CAT6 mice was similar to that observed in pHST(368/62)-CAT6 mice (Fig. 2B). In both groups of animals CAT activity appeared in extracts from testes of 15-day-old mice (when pachytene spermatocytes were fully developed), increased markedly in extracts from testes of 22-day-old mice (when spermatids were formed) and reached the maximum in sexually mature animals.

The EcoRV-ApaI restriction fragment of the rat $H s t 70$ gene promoter encompasses a sequence that has a strong similarity to the cis-acting element from the promoter of a testis-specific histone $\mathrm{H} 1$ gene termed TE1 (Grimes et al., 1992). In addition, the $5^{\prime}$ part of box $\mathrm{B}$ contains a sequence that differs by only one nucleotide from the estrogen responsive element (ERE) consensus sequence that was termed ERE-like. However, our previous experiments with the Hst70 gene promoter showed that the ERE-like sequence did not respond to hormone stimulation in a transient transfection assay (Krawczyk et al., 1993) and that the TE1-like element did not bind any specific testicular proteins in vitro (Ścieglińska et al., 2004). Those data suggest that neither the TE1- 


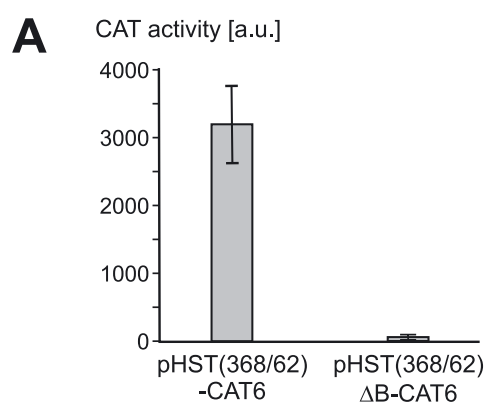

B

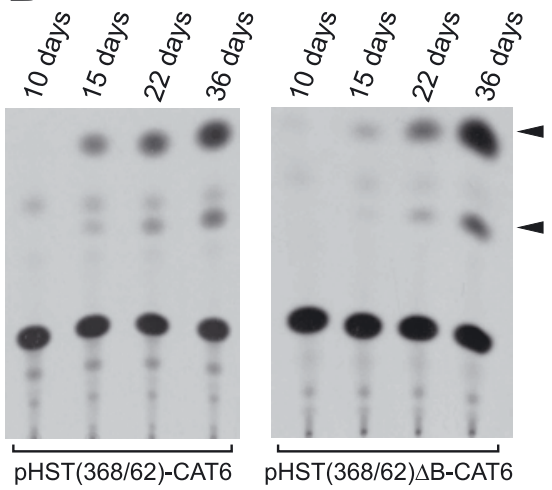

Figure 2. Removal of box $B$ and its adjacent sequences from the Hst70 gene promoter reduces the overall expression of the $C A T$ reporter gene yet the stage-specific expression pattern of the transgene is preserved in testes of transgenic mice.

(A) Comparison of the CAT activity in testes of adult transgenic mice. Four different lines carrying either the pHST(368/62)-CAT6 or the pHST(368/62) BB-CAT6 transgene were analyzed in triplicate. The CAT activities (mean values and standard deviations) are expressed in arbitrary units. (B) The CAT activities were analyzed in extracts from testes of pHST(368/62)-CAT6 and pHST(368/62) $\Delta \mathrm{B}$ CAT6 transgenic mice of different age. $25 \mu \mathrm{g}$ of protein and $15 \mathrm{~min}$ of reaction time or $50 \mu \mathrm{g}$ of protein and $5 \mathrm{~h}$ of reaction time were used, respectively. Acetylated forms of chloramphenicol are marked with arrowheads.

like nor the ERE-like sequence present in box B has a functional importance. However, removal of the EcoRV-ApaI restriction fragment, in addition to the box B elimination, affects adjacent GATA- and GCboxes (Fig. 1). GC-boxes, alternatively termed Sp1binding sites, are particularly rich in $\mathrm{G}$ and $\mathrm{C}$ nucleotides and potentially bind the Sp1-like transcription factor (reviewed in Kaczynski et al., 2003). Our earlier examination of the pHST(368/62)-CAT6 transgene, where the $\mathrm{T} 2$ transcription start site and proximal sequences including part of the same putative GCbox [SmaI(-203)-DraII(-62) fragment] were replaced with the minimal tk promoter (Ścieglińska et al., 2004), showed reduction of the CAT activity similar to that observed for the pHST(368/62) $\triangle \mathrm{B}-\mathrm{CAT} 6$ transgene (Fig. 2). Both complementary experiments with deleted the $-279 /-205$ and $-203 /-62$ fragments of the Hst70 promoter pointed to the potential importance of the GC-box within apparently the $-214 /-200$

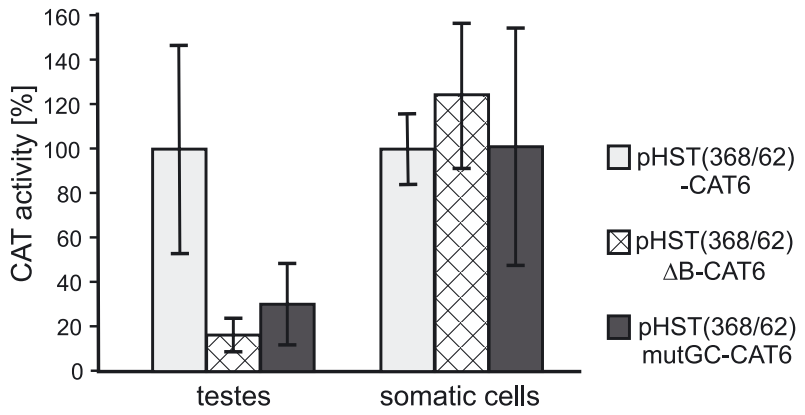

Figure 3. The GC-box present in Hst70 promoter is required for its activity in spermatogenic cells.

Comparison of the CAT activity in testes electroporated in vivo and HCT116 cells transfected in vitro (somatic cells) with either pHST(368/62)-CAT6, pHST(368/62) $\triangle \mathrm{B}-\mathrm{CAT6}$ or pHST(368/62)mutGC-CAT6 plasmid. Values (means from 3-6 independent experiments) are expressed as percentage of CAT activity of the pHST(368/62)-CAT6 construct (taken as $100 \%$ ).

sequence. Here we aimed to directly verify the potential importance of the GC-box located downstream of box B for regulation of the Hsp70.2/Hst70 promoter, and analyzed the activity of the promoter with a mutated GC-box.

The whole GC-rich fragment (-223/-196) of the Hst70 promoter was replaced in the initial pHST(368/62)-CAT6 construct by PCR-mediated mutagenesis and the resulting construct was termed pHST(368/62)mutGC-CAT6 (Fig. 1). Activities of the pHST(368/62)mutGC-CAT6, pHST(368/62)-CAT6 and pHST(368/62) $\triangle$ B-CAT6 constructs were analyzed in either testes electroporated in vivo or in somatic cells transfected in vitro (Fig. 3). Importantly, both the removal of box $\mathrm{B}$ with adjacent sequences and mutation of the GC-box reduced the Hst70 promoter activity in spermatogenic cells to a similar extent (Fig. 3). On the other hand, neither mutation of the GC-box nor removal of box B affected the Hst70 promoter activity in transiently transfected HCT116 somatic cells. These data indicate that the trans-acting regulatory elements that interact with the GCbox and/or the other sequences around exon1/intron splicing site are specific for spermatogenic cells.

We atempted to further analyze the presence of putative tissue-specific proteins that may interact with the GC-box from the Hsp70.2/Hst70 promoter. The electrophoretic mobility-shift assay was used to detect complexes formed in vitro between nuclear proteins and radioactive DNA probes (Fig. 4). Three $30 \mathrm{bp}$-long radioactive probes were used: the consensus sequence for the human Sp1 binding site (Kadonaga et al., 1987), the GC-box from the Hsp70.2/ Hst70 promoter, and the mutated GC-box (the same sequence as in the pHST(368/62)mutGC-CAT6 construct). Nuclear proteins were extracted from mouse liver (where the Hsp70.2/Hst70 gene expression is 


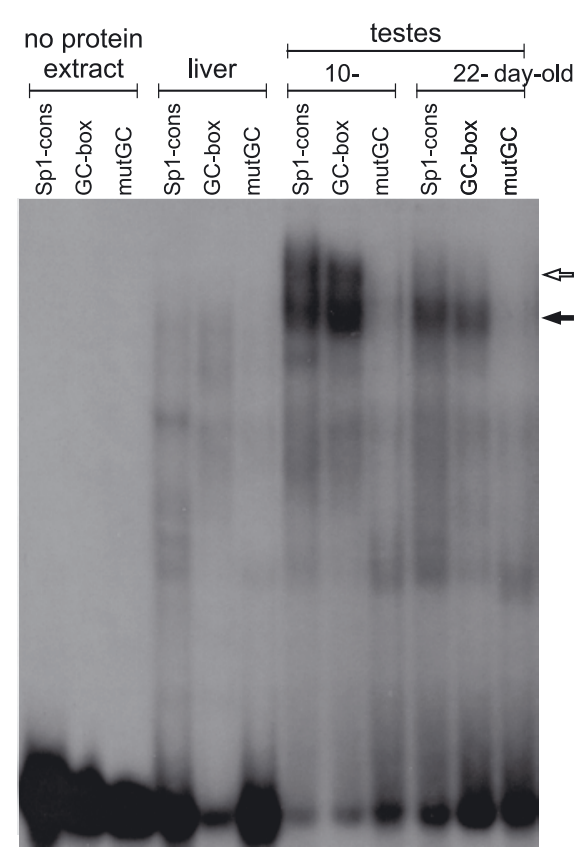

Figure 4. Spermatogenic cells contain proteins that specifically interact with the GC-box from the Hsp70.2/Hst70 gene promoter.

Complexes were formed in vitro between DNA probes containing either Sp1 binding site consensus (Sp1-cons), GC-box from the Hsp70.2/Hst70 gene (GC-box) or mutated GC-box (mutGC), and proteins from nuclear extracts from liver or testes of 10- and 22-day-old mice. Arrows indicate the positions of the major complexes.

permanently blocked), testes of 10-day-old mice (before the appearance of spermatocytes and corresponding activation of the Hsp70.2/Hst70 gene), and testes of 22-day-old mice (that contain spermatocytes and round spermatids with the active Hsp70.2/ Hst70 gene). We observed that the GC-box from the Hsp70.2/Hst70 promoter, but not the mutated sequence, efficiently formed complexes with nuclear proteins from testes but not those from liver. Similar complexes were formed between proteins from testes (but not those from liver) and the Sp1 binding site consensus (the specificity of the complexes was verified using the same non-radioactive sequences as homologous competitors; data not shown). This indicates that the GC-box from the Hsp70.2/Hst70 promoter binds Sp1-like factors, and that the amounts of such proteins are higher in testes as compared to liver extracts. More interestingly, two different nucleoprotein complexes that contained the GCbox were detected with the testicular extracts from 10-day-old mice. However, the lower-electrophoretic-mobility complex could not be detected with testicular extracts from 22-day-old mice, in which the Hsp70.2/Hst70 gene is activated. Taken together our observations suggest that certain testis-specific proteins that bind to the GC-box might function as transcriptional activators while others might be transcriptional repressors in younger males (when the
Hsp70.2/Hst70 gene is inactive). A similar repressor function was previously reported for a protein that bound to the Oct sequence in juvenile testes and was released after the $H s p 70.2 / H s t 70$ gene activation in spermatocytes (Ścieglińska et al., 2004).

GC-boxes are among the most common cisregulatory elements widely distributed in promoters, enhancers and locus control regions of numerous genes, either housekeeping or tissue-specific ones. They are also involved in regulation of several genes specifically expressed in differentiating mouse germ cells, such as $L d h$ family members (Bonny et al., 1998; Thomas et al., 2005), Pgk2 (Gebara \& McCarrey, 1992), Pdha2 (Iannello et al., 1993; 1997) and histone H1t (Wilkerson et al., 2002). GC-boxes are recognized by a group of transcription factors that contain a highly conserved DNA-binding domain consisting of three zinc fingers (Sp1-like/KLF family) (reviewed in Kaczynski et al., 2003). Among the proteins that are likely to bind to the Hsp70.2/Hst70 GCbox is the Spl transcription factor, which is abundant in testes (as well as in thymus and prostate), while its concentration is low in most somatic tissues (Saffer et al., 1991; Robidoux et al., 1992). Several Sp1 isoforms are expressed in spermatocytes, e.g. 110 $\mathrm{kDa}, 90 \mathrm{kDa}$ and $60 \mathrm{kDa}$ SP1 proteins (Persengiev et al., 1996; Thomas et al., 2005). However, the identity of the putative transcription factor interacting with the Hsp70.2/Hst70 GC-box and its exact role in the $\mathrm{Hsp} 70.2 / \mathrm{Hst70}$ gene regulation remain to be established.

\section{Acknowledgements}

This work was supported by the Ministry of Science, Grants 3P05A00925 to D.Ś. and 2P04A04030 to W.W.

V. Dudaladava was sponsored by an NCI Fellowship. N. Vydra was sponsored by The Foundation for Polish Science (Grant for Young Scientists).

\section{REFERENCES}

Allen RL, O'Brien DA, Jones CC, Rockett DL, Eddy EM (1988) Expression of heat shock proteins by isolated mouse spermatogenic cells. Mol Cell Biol 8: 3260-3266.

Bonny Ch, Cooker LA, Goldberg E (1998) Deoxyribonucleic acid-protein interactions and expression of the human testis-specific lactate dehydrogenase promoter: transcription factor Spl plays a major role. Biol Reprod 58: 754-759.

Bonnycastle LLC, Yu Ch-E, Hunt CR, Trask BJ, Clancy KP, Weber JL, Patterson D, Schellenberg GD (1994) Cloning, sequencing, and mapping of the human chromosome 14 heat shock protein gene (HspA2 ). Genomics 23: 85-93.

Dix DJ, Allen JW, Collins W, Mori C, Nakamura N, Poorman-Allen P, Goulding EH, Eddy EM (1996) Targeted gene disruption of Hsp70-2 results in failed meiosis, 
germ cell apoptosis, and male infertility. Proc Natl Acad Sci USA 16: 3264-3268.

Gebara MM, McCarrey JR (1992) Protein-DNA interactions associated with the onset of testis-specific expression of the mammalian Pgk-2 gene. Mol Cell Biol 12: 14221431.

Grimes SR, Wolfe SA, Koppel DA (1992) Tissue-specific binding of testis nuclear proteins to a sequence element within the promoter of the testis-specific histone H1t gene. Arch Biochem Biophys 296: 402-409.

Iannello RC, Kola I, Dahl HH (1993) Temporal and tissuespecific interactions involving novel transcription factors and the proximal promoter of the mouse Phda-2 gene. J Biol Chem 268: 22581-22590.

Iannello RC, Young J, Sumarsono S, Tymms MJ, Dahl HH, Gould J, Hedger M, Kola I (1997) Regulation of Phda-2 expression is mediated by proximal promoter sequences and CpG methylation. Mol Cell Biol 17: 612-619.

Kaczynski J, Cook T, Urrutia R (2003) Sp1- and Krüppellike transcription factors. Genome Biol 4: 206.

Kadonaga JT, Carner KR, Masiarz FR, Tjian R (1987) Isolation of cDNA encoding transcription factor SP1 and functional analysis of the DNA binding domain. Cell 51: 1079-1090.

Krawczyk Z, Wiśniewski J, Biesiada E (1988a) A rat testis-specific hsp70 gene-related transcript is coded by a novel gene from the hsp70 multigene family. Acta Biochim Polon 35: 377-385.

Krawczyk Z, Mali P, Parvinen M (1988b) Expression of testis-specific hsp70 gene-related RNA in defined stages of rat seminiferous epithelium. J Cell Biol 107: 1317-1323.

Krawczyk Z, Schmid W, Harkonen P, Wolniczek P (1993) The ERE-like sequence from the promoter region of the testis specific hsp70-related gene is not estrogen responsive. Cell Biol Int 17: 245-253.

Persengiev SP, Raval PJ, Rabinovitch S, Millette CF, Kilpatrick DL (1996) Transcription factor Sp1 is expressed by three different developmentally regulated messenger ribonucleic acids in mouse spermatogenic cells. Endocrinology 137: 638-646.

Pothier F, Ouellet M, Julien JP, Guerin SL (1992) An improved CAT assay for promoter analysis in either transgenic mice or tissue culture cells. DNA Cell Biol 11: 83-90.

Robidoux S, Gosselin P, Harvey M, Leclerc S, Guerin SL (1992) Transcription of the mouse secretory protease inhibitor p12 gene is activated by the developmentally regulated positive transcription factor Spl. Mol Cell Biol 12: 3796-3806.

Saffer JD, Jackson SP, Annarella MB (1991) Developmental expression of Spl in the mouse. Mol Cell Biol 11: 21892199.

Ścieglinska D, Widłak W, Konopka W, Poutanen M, Rahman N, Huhtaniemi I, Krawczyk Z (2001) Structure of the $5^{\prime}$ region of the hst70 gene transcription unit presence of an intron and multiple transcription initiation sites. Biochem J 359: 129-137.

Ścieglińska D, Vydra N, Krawczyk Z, Widłak W (2004) Location of promoter elements necessary and sufficient to direct testis-specific expression of the Hst70/Hsp70.2 gene. Biochem J 379: 739-747.

Thomas K, Sung D-Y, Yang J, Johnson K, Thompson W, Millette C, McCarrey J, Breitberg A, Gibbs R, Walker W (2005) Identification, characterization and functional analysis of Sp1 transcript variants expressed in germ cells during mouse spermatogenesis. Biol Reprod 72: 898-907.

Widłak W, Markkula M, Krawczyk Z, Huhtaniemi I (1994) Functional analysis of spermatocyte-specific hst70 gene promoter in transgenic mice. Acta Biochim Polon 41: 103-105.

Widłak W, Markkula M, Krawczyk Z, Kananen K, Huhtaniemi I (1995) A 252 bp upstream region of the rat spermatocyte-specific hst70 gene is sufficient to promote expression of the hst70-CAT hybrid gene in testis and brain of transgenic mice. Biochim Biophys Acta 1264: 191-200.

Widłak W, Ścieglińska D, Vydra N, Małusecka E, Krawczyk Z (2003) In vivo electroporation of the testis versus transgenic mice model in functional studies of spermatocyte-specific $h s t 70$ gene promoter. A comparative study. Mol Reprod Dev 65: 382-388.

Wilkerson DC, Wolfe SA, Grimes SR (2002) H1t/GC-box and H1t/TE1 elements are essential for promotor activity of the testis-specific histone H1t gene. Biol Reprod 67: 1157-1164.

Zakeri ZF, Wolgemuth DJ, Hunt CR (1988) Identification and sequence analysis of a new member of the mouse HSP70 gene family and characterization of its unique cellular and developmental pattern of expression in the male germ line. Mol Cell Biol 8: 2925-2932. 